\title{
What does the actor need to perform in healthcare? Emotional demands, skills and competences.
}

\begin{abstract}
This article aims to explore the required skills and competencies of the actor within the healthcare. The collection of raw text qualitative data and inductive thematic analysis is used to allow findings to emerge from frequent or significant themes inherent in raw semi-structured interview data. Data was collected by ten narrative interviews with experienced actors in hospitals and, Drama trainees. This narrative inquiry gave opportunity for participants to elaborate on their understandings of their direct or indirect engagement with theatre in hospitals. The study demonstrates a defensible emphasis on key themes including, more obvious professional skills such as acting in participatory dramas, using theatre improvisation and puppetry, and interpersonal skills such as emotional intelligence and empathetic awareness.
\end{abstract}

Key words: applied theatre skills; emotional intelligence; empathy; qualitative

\section{Introduction}

The body of research that supports the beneficial role of diverse applications of applied theatre in relation to health and wellbeing of populations in public health such as hospitals, hospices and care homes has grown considerably in the U.K. in recent years (APPG 2017). Research on government policy-making and health care services (Parkinson and White 2013) and the methodologies linking theatrical interventions to individuals and communities in clinical contexts (Baxter and Low 2018; Sextou 2016; Brodzinski 2010) attest to the value of value theatre. More specifically, research evidence captures the perceived wellbeing benefits of using interactive bedside performance with children in hospitals (Sextou and Hall 2015), from drama with older people that transforms patterns of doing, thinking and feeling as a route to wellbeing (Wimpenny and SavinBaden 2014) and, from participatory theatre with people who experience recovery from mental health issues (Torrissen and Stickley 2018). These studies demonstrate how arts projects in healthcare have provided a valuable means to create new ways of creative engagement with vulnerable audiences. However, there is little evidence on the needs of the artist and the skills and competencies that they need to perform in healthcare sensitively and professionally.

The literature suggests that further investigations are necessary in the training of artists in health care (Moss and O'Neill 2009); more specifically, there is a need for 'the development of undergraduate and postgraduate courses and professional modules dedicated to the contribution of the arts to health and wellbeing' (APPG 2017:155-156). The authors acknowledge the demand in this field, particularly in relation to the complexities and emotional demands of the location. In this study, therefore, we aimed 
to develop a better understanding of the behaviours and incidents that actors witness on hospital wards, how they respond to them as artists, what skills they use and what they recommend as useful practice for actors in healthcare. This study's aim was to contribute to discussions about the skills of artists in healthcare; the article argues for the development of new courses in applied theatre and, more generally, in arts and health.

\section{Rationale}

Building on the research and literature, this project acknowledges that working in child health care is stressful (Pelander and Leino-Kilpi 2010). Numerous research studies suggest high levels of work-related stress, exhaustion and burnout amongst child healthcare practitioners (Pantaleoni et al. 2014). Paediatric health-care professionals often deal with demanding situations that may induce strong emotional reactions (Mukherjee et al. 2009). Emotional burnout has also been reported by nurses who work with children with chronic conditions (Maytum, Heiman and Garwick 2004). Considering that strong emotions are implicit elements in health-care interactions, there is currently an increasing interest in enlisting emotionally competent personnel in healthcare (Stratton, Sauders and Elam 2008). Indeed, the skills to understand use and regulate emotional information in oneself and others have recently been acknowledged as compulsory to ensure a high quality of health-care service (Birks and Watt 2007). Lee and colleagues (2015) argue that the abilities related to emotional intelligence could be important predictors of professionals' wellbeing and resilience in intensive care paediatrics, where efficiently adapting to emotionally demanding conditions could be a core requirement. Because theatrical interactions in hospitals take place in a situation fraught with strong emotions, marginalisation, risk, trauma and suffering caused by illness, the authors of this study start from a premise that performing in child health care can be an emotionally demanding. It is necessary to explore the practitioner's ability to deal with the demands of the location both efficiently and professionally.

\section{Methodology}

To contextualise the study in relation to the demands placed on both audiences and actors by theatre in clinical settings, we include a brief description of artistic practice based on our personal experience.

Hospital performances for children are generally interactive, improvisatory and flexible interventions. They aim to engage the audience in creative distractions from their clinical condition, help them relax and bring normality to their stay in hospital. Some of these performances are more intimate than others and can happen one to one at the bedside, while others target small groups of children in the same room. Performances may vary in content, length, style and techniques (e.g. interactive storytelling, puppetry) to suit the preferences of the artist and the needs of the audience (for example, blind children would benefit from sensory activities). Hospital performances are intended to be inclusive because audiences come from various cultural and social backgrounds. Communication can be challenging. Some children have English as their second 
language and others have limited verbal skills. Children with developmental delays may also have limited ability to communicate well. When possible, the artist facilitates onverbal communication. The audiences' level of engagement may also vary depending on the children's age, moods and the seriousness of their health condition. The artist has to follow the hospital's safety policies and health regulations, which may put restrictions on using materials, costumes and props, and on what decisions can be made about the dimensions of the performance space. These can be overcome by a collaboration between the artist and the clinical staff. In hospitals, the artist is in a process of continuous negotiation between accepting illness as reality and transforming the hospital experience in positive ways through theatre.

For the purposes of this pilot study, we employed a raw text qualitative method. Face-toface, semi-structured, audio-recorded interviews of set questions were used to offer space for divergence and to allow a flow of ideas and answers (Wisker 2009). We used interviews to explore the views of research participants on any deviation from traditional acting training, where the body and the text are the main working sources, into an awareness of the body and emotions (Bryman 2008). The interviews lasted approximately one and a half hours each, and were carried out at the premises of a higher education institution in the United Kingdom over a period of seven months (December 2016 to August 2017).

The method that has been used for data analysis is inductive thematic analysis (Thomas 2006), to allow findings to emerge from frequent or significant themes inherent in interview data. The approach is not limited by prior assumptions and theories or hypothesis as in deductive analysis, but rather welcomes any unplanned effects or sideeffects arising from the study. Emerging themes were developed by studying the transcripts repeatedly and considering possible meanings. We coded our reviews of the transcripts separately and in parallel to make the process more objective.

\section{Research participants}

Ten research participants took part in this pilot study. These were five applied theatre practitioners (ATPs) holding an acting qualification either from a higher education institution (HEI) or an acting school, and five Drama trainees (DTs) who were attending an undergraduate Drama degree with focus on applied theatre in HEIs at that time. The ATP participants had previous direct practical experience of performing to patients in public health care for a period of one to six years. The DTs had one to three years' experience of observing various ATPs (other than the participants) delivering theatrical interventions in clinical settings during their studies. Eight of the participants were female and two were males. This reflects gender gap that traditionally exists in Drama subjects at UK Universities (The Guardian Education 2013).

The guiding principle for this pilot study was to provide a voice for the ATPs and DTs to identify the daily encounters of performing in clinical settings and the skills they needed to deal with them. Although we acknowledge that hospitals are emotionally demanding 
environments demanding emotionally competent personnel in health care, we decided not to ask direct questions about their emotional competences but rather ask them to talk about their direct or indirect experience of hospital performance and be open to the emerging data.

The interviews were divided into three main parts. The first part focused on the participants' knowledge of applied theatre practices and approaches to health care generally, and their previous experience in this filed. Our aim was to understand whether or not the participants were acquainted with theatre practice in health care. Sample questions were:

How do you perceive an actor's role in healthcare?

What is your experience of hospital performance?

In the second part, the focus was on the participants' experiences of using hospital as a 'stage', as opposed to performing in the main house theatre. Our goal was to explore what factors define hospital performance. Sample question were:

What child behaviours and incidents do you normally experience during theatrical interventions on hospital wards (either directly or indirectly)? Can you give us an example?

Can you recall how you responded to that incident as an artist?

The third part of the interviews aimed to elicit the participants' views on the skills required to perform effectively in health care and give voice to their recommendations. Sample questions were:

What skills are necessary, in your view, to ensure efficiency and professionalism in hospital performance?

Can you give us an example of using (or observing) one of those skills in context?

Ethical approval for the study was granted through the authors' HEI Research Ethics Committee. All participants received information sheets about the study prior to the interviews by email and gave their written consent. The interviews were audio recorded and transcribed.

\section{Discussion of findings}

The analysis of data suggests that at times the emerged themes are unified and interconnected. Most of the research participants refer to professional acting skills in relation to interpersonal competencies showing some difficulty in separating them. We would like to think that this 'difficulty' is not necessarily a weakness. On the contrary, it may be an indication of interrelated links between the professional role of the applied theatre practitioner and the interpersonal, more delicate side of the job that deals with 
emotions and needs soft skills. Consequently, it became more sensible for us to view the themes as equally important and dynamic entities that were related to one another. In accordance to the aim of the study, this allowed us, in accordance to the aim of the study, to discuss the participants' views together rather than separately. Significant frequent themes were evinced frequently in two main interrelated areas of discussion: (1) participatory acting, improvisation and puppetry; and (2) emotional intelligence, emotional awareness and empathy.

When we asked the participants what behaviours and incidents they had experienced during hospital performance, they reported both positive and less positive incidents and behaviours. Positive experiences generally involved performances to children who were open to communication and responsive. Less positive experiences involved incidents that affected performances in some ways - for example, audiences that were distracted by clinical procedures taking place during performance and by emergencies that happened to other children on the same ward.

We asked the participants about their own experience of such incidents seeking a better understanding of how the actors felt and, how they dealt with them during performance. We expected a variety of individual response; participants were not likely to respond to the environment consistently, because they came with different levels of experience and familiarity with clinical environments. Some DTs revealed anxiety about performing to sick children. ATPs generally reported confidence and enjoyment during performance. More specifically, the more experienced an ATP was in performing in health-care settings, the more confident they appeared to be in using the aesthetics of performance to remain focused and professional.

Six of participants, both ATPs and DTs, mentioned the word 'distance' to describe their experience of hospital performance. They reported:

'You need some quiet focus when lots of things are going on around you to provide distance for yourself.' (DT)

'I wouldn't want to shut myself off because I don't think that's effective but provide some distance for myself to protect me so that I can go on and perform'. (DT)

'In dealing with challenging situation when a nurse rushes into the room, you must react in character, you know what I mean, not to break the aesthetics of the piece, just because something is happening and keep your distance.' (ATP)

All ATP participants with direct experience of hospital performance suggested some competencies that helped them to maintain a professional distance from the emotional information communicated by children on the wards. They suggested adaptability to situations, presence in the now, calmness, self-awareness and professionalism. 
'You have to be adaptable which is hard because you have to be in the moment with the story but then you can't completely get lost in it because you have to be aware of what's going on around you at all times so that there's a balance [...]' (ATP)

'[...] you need to be calm, considered with the role that you have took on, need to be aware of who you are and who the child thinks that you are, to not break that fiction that you have created that's not real, acting skills, you know!' (ATP)

The competences described by these participants are not unknown to applied theatre practitioners. The aesthetics of participatory performance allow us to enter an imaginative world-even though we are aware that it is not completely separate from reality. The audience is a contributor to interactive performance rather than a passive recipient of a complete artistic product (Jackson 2007). Therefore, distancing from reality becomes a complicated problem in participatory dramas. The barriers between reality and fiction are lifted to allow interaction between actors and audiences. To bring this notion in hospital performance, the actor and the child share a story that is separate from the hospital reality but because it takes place within a dominant context and setting, reality can't be ignored, as the research participants suggested.

When we asked the participants to give us examples of behaviours or incidents on the wards that couldn't be ignored during performance, a participant described an incident with a nurse who interrupted the intervention to take a blood test. The child was unwilling to cooperate in taking the blood test because of previous bad experience of finding a vein. He cried and made noises. We asked the participant how that had felt and he had dealt with:

'There has to be a degree of attachment but you can't get too emotionally involved, you might get upset, I suppose you've got to keep that professionalism [...] but at the same time you've got to show your emotions as well so it's a delicate balance I guess between showing that side of emotion to do with the performance and that's acting as well, isn't it?' (ATP)

The limitations of distancing in participatory theatre in health care and the requirement to reflect on emotions were also acknowledged by other participants:

'Something might happen during the session and a doctor has to come in at which point you need to be aware of what's going on, you need to be a caring professional'. (ATP)

'You have to be friendly, welcoming, have empathy to the child [...] you have to be sensitive to the whole experience, and caring and have patience and reflect on emotions.' (DT) 
These statements suggest a process of dealing with real incidents during performance that involves mindfulness of emotions and attentiveness. Thompson (2015) argues that attentiveness and care are at the heart of applied theatre practice in health care, and are the outcome of a sensitive and ethical approach to performance in challenging environments. In the context of hospital performance, being a caring professional seems an obvious competency. Working with children affected by health conditions requires a practice of kindness and compassion. Yet, it is possible for an actor to be caring towards a sick child as an audience without responding to the child's identity as a sick person? Who does the actor care for: the child as participant or the child as a patient or both? If we accept that a child in hospital has 'a dual citizenship' as a citizen in the 'province of illness' (patient) and a citizen of fantasyland (audience), then performing to a sick child would be no different to acting in metaxis, a generally recognised condition in applied theatre, defined as bringing the two almost autonomous worlds of fiction and reality together in interactive participatory dramas. The dialogue between the world of the audience and the world of the play is known as the context of "metaxis" in the Theatre of the Oppressed (Boal 1995). The word 'metaxis' might not have been in the vocabulary of the participants but they described it. Their replies showed that when they perform in hospital, they are present in and belonged to two different words: the fictional story and the reality of illness. Performing 'in between' two worlds is a skill required by actors in participatory theatre that seems to work well for actors in health care. It may be that it helps them to balance their focus and respond to the demands of the location. It seems that incorporating that experience in their acting and showing emotions in character is part of what it means to be an actor.

We asked the participants what skills were necessary to ensure efficiency and professionalism in hospital performance. Eight participants talked about puppets as the children's most favourable tools for engaging them with the fictional. Two ATPparticipants who employed puppetry in their work found puppets 'helpful in encouraging communication' with audiences and they suggested 'collaboration between actors and puppeteers'. More specifically, they said:

'...Obviously, the kids can relate to that (puppets) because they play with a lot of toys and it's easy to use puppets to mask everything when you are performing alone one-to-one to a child.' (ATP)

'Instead of using my body to bring the story I am using a puppet and I am projecting on to it to bring the story to life and it all becomes more engaging.' (ATP)

For two Drama students who observed interventions, puppets are represented as excellent tools for making safe emotional connection with the audience:

'Puppets take children's minds off [...] they remind them of home'. (DT) 
'It is very important to tell a story through a puppet [...] it makes it more relatable and safer.' (DT)

Puppets are exemplars of emotional protection in creative interventions (Adams 2008). Creative interactions with puppets have been widely used with children in therapy to foster healing, engage the child, generate a rich description of their experience, and facilitate the imaginative creation of new meanings (Desmond et al. 2015). Puppets are also used in paediatrics by play specialists to take the child's mind off clinical procedures, and the pain and fear associated with them (Great Ormond Street Hospital NHS 2018). The participants appreciated puppets as tools to engage children in the story, and to keep them focused and connected to fiction; some of them used puppets as a source of playing and normalising their hospital experience.

Four practitioners, all ATPs with experience, acknowledged empathetic awareness of self and others as a critical element of their work in hospitals. An ATP with six years' experience of performing in health care said:

'You can't get completely lost in your role and your lines. You've got to be concentrated on your role but also have a greater sense of awareness of yourself and what goes on in your surroundings and know how to respond to your emotions [...] a lot of it is about Emotional Intelligence, understanding yourself, understanding the child, and how you might react to this situation thinking about how you come across to the child in that situation and what the child's face tells you and what your language and what your face and your body is doing to that child at that moment.' (ATP)

Another ATP mentioned attentional skills:

'I think you get yourself into a frame of mind before you go in. You can't ignore your emotions, you are in role and so I think it is beneficial. You are not on your own, you are able to connect with the audience because you are in-role in the moment.' (ATP-2 years of experience)

The above quotes coincide with Goleman's theory (2014) of focus and the importance of being aware of our own awareness. According to Goleman, focus helps us to handle emotions, our inner world and our thoughts and to manage them for the better. In the context of performing for sick children, focus relates to the perspective actors can take that allows them to monitor their inner world and remain professional during challenging incidents. Lee and colleagues (2015) also argue that Emotional Intelligencerelated abilities could be important predictors of professionals' wellbeing and resilience in intensive care paediatrics, where the ability to efficiently adapt to emotionally demanding conditions could be a core requirement. According to Mayer and Salovey (1997), Emotional Intelligence is concerned with the individual's ability to use emotional information to facilitate various cognitive processes, such as information processing, focus of attention and decision-making. We appreciate that these theories need further 
discussion in future studies because they may be particularly useful approaches for actors in health care, especially when they encounter unpredictable emotional incidents during performance.

The study offers indications that empathy and improvisation are concepts worth exploring. Interviews revealed participants' recognition of empathising with the patientaudience's situation in developing interaction with the audience:

'theatre and empathy go hand in hand I think because you need to understand the people you perform to and so you can treat them like people opposed to sick children.' (DT)

'...just have to show to the child that you, as a person, understand they are going through a difficult time [...] and give them a chance for communication as an empathetic person and in a greater understanding a non-judgmental person'. (ATP)

'if for example a child is in hospital and we are performing, and somebody comes, and I must improvise but I can see the child is distressed, I would be able to show empathy through my improvisation. I mean so I wouldn't improvise in a way that was static and robotic, I would improvise in a way which was tailored to the situation [...]. So, if you can show empathy in that moment of improvisation, and if you can improvise with the story in empathy, the child is relaxed, and they are like 'the practitioners are right there with me, and we're in synch in a way'.

Empathy involves a deep understanding of the patients' inner self and experiences, as opposed to sympathy which involves the action of affective joining with the patient (Fields, et al. 2011). Understanding the emotions and experiences of others may assist ATPs to take a caring and compassionate approach to their practice; maintain personal wellbeing; provide good quality of social support to colleagues and establish positive interpersonal interaction with the audience. While empathising with the audience in real incidents, improvisation could be of great assistance in incorporating incidents and emotions from reality into the dramatic dimensions of the story in a natural way. Understanding experiences and responding to them in the context of this article could benefit the actor from engaging their ability to deal with what may be a stressful incident in child health-care and other community contexts.

\section{Concluding thoughts, aspirations and recommendations}

Actors in healthcare belong to a wider group of artists who work with children in hospital, including clowns known as giggling doctors, storytellers, puppeteers, magicians, musicians, singers, visual artists, and so on. Some of the findings about the specific skills required of an actor in child health care may also apply to professionals in the same or similar contexts. The findings of this study might form a basis for further 
recommendations that would improve the provision of training of a larger group of artists across the arts in health and wellbeing sector.

We are aware of the limitations of a pilot study (i.e. small sample, short period, one method), but we are confident to argue that the present study reveals useful indications of important concepts that are generally under-investigated, including the distinctive demands of the hospital location on human emotions during theatrical interventions and the role of aesthetics in emotional protection. More specifically:

1. Hospital performances in child health care are representative examples of applied theatre practice that involves participatory acting and improvisation, and efficiency in bringing reality and fiction into a collaborative dialogue in performance.

2. Actors are required to develop an all-round awareness of emotions during performance, including those of their own and their audiences.

3. Actors need to be adaptable to situations, present in the now, calm, self-aware, emotionally aware, professional, friendly and welcoming, have empathy to the child, be sensitive to the whole experience, caring, patient and reflective about their emotions (they must have emotional intelligence and empathetic awareness).

4. Actors would benefit from hands-on practical experience and opportunities to familiarise themselves with the clinical environment and gain confidence in hospital performance.

We recommend further investigations in the form of larger studies in this field to understand better the training needs of actors in health care concerning emotional protection in interactive applied theatre performances.

1. The concept of Emotional awareness, intelligence and attentiveness may play a particularly important role in applied theatre with vulnerable audiences (i.e. sick children, young people at risk, young offenders, elderly people in care homes, audiences in prisons, rehabilitation centres, palliative care services and in refugee camps).

2. The beneficial role of puppetry in hospital performance for children also generates further research aspirations for future investigation examining whether puppetry in hospital performance is a way to maintain the fictional while interchanging information and emotions with the surroundings outside the performance.

Arguably, the degree to which an ATP can moderate levels of stress during performance in clinical surroundings is subject to individual differences (Birks and Watt 2007). Therefore, if emotional intelligence and empathetic awareness affect applied theatre programmes then it will be important to determine whether emotional intelligence and empathy can be improved by training, what kind of training. Thereis a need to also determine what kind of training would be effective on the ATP's work and 
whether an ATP's emotional intelligence score would matter in their choice to work in health care.

How actors employ and apply their skills to various situations may vary from person to person and from performance to performance. We recommend additional research with larger groups of participants in studies with longitudinal impact. We suggest crossdisciplinary research between Theatre and Psychology and Creative Therapies professions aiming to develop a new body of combined knowledge and expertise. This may challenge traditional contexts of applied theatre by exploring wider social and personal aspects of development; such as discovering one's self and emotional existence, being aware of people's needs, caring for individuals and communities and finding meaning in professional and personal life through theatre in health care. If that requires a change in the culture of applied theatre education and work spaces, the question is whether we are ready to dear to undertake this innovation.

\section{REFERENCES}

Adams, S. (2008), 'Banishing gooos and taits: The story of narrative therapy use in a grade three classroom', Relational Child \& Youth Care Practice, 21:1, pp. 42-46.

APPG (All-Party Parliamentary Group (Inquiry Report on Arts, Health and Wellbeing) (2017), 'Creative Health: The Arts for Health and Wellbeing', http://www.artshealthandwellbeing.org.uk/appginquiry/Publications/Creative Health Inquiry Report 2017.pdf Accessed 22 August 2017.

Baxter, V. and Low, K. (eds) (2017), Applied Theatre: Performing Health and Wellbeing. London: Bloomsbury.

Birks, Y. and Watt, I. S. (2007), 'Emotional intelligence and patient-centred care', Journal of the Royal Society of Medicine, 100:8, pp. 368-374.

Boal, A. (1979), Theatre of The Oppressed. UK: Pluto Press.

Brodzinski, E. (2010), Theatre in Health and Care. London: Palgrave Macmillan.

Bryman, A. (2008), Social Research Methods. Oxford: Oxford University Press.

Desmond, K., Kindsvatter, A., Stahl, S. and Smith, H. (2015), 'Using Creative Techniques With Children Who Have Experienced Trauma', Journal of Creativity in Mental Health, 10:4, pp. 439-455.

Fields, SK., Mahan, P., Tillman, P, Harris, J. Maxwell, K., and Hojat, M. (2011), 'Measuring empathy in healthcare profession students using the Jefferson Scale of Physician 
Empathy: health provider--student version', Journal of Interprofessional Care, 25:4, pp. 287-93.

Goleman, D. (2014), Focus: The Hidden Driver of Excellence. UK: Bloomsbury.

Great Ormond Street Hospital NHS (2018), 'Distraction therapy' https://www.gosh.nhs.uk/medical-information-0/procedures-and-treatments/distractiontherapy. Accessed: 22 August 2018.

Jackson, A. (2007), Theatre, Education and the making of Meanings. UK: Manchester University Press.

Lee, K. J., Forbes, M. L., Lukasiewicz, G. J., Williams, T., Sheets, A., Fischer, K., and Niedner, M. F. (2015), 'Promoting staff resilience in the pediatric intensive care unit', American Journal of Critical Care: An Official Publication, 24:5, pp. 422-430.

Mayer, J. D. and Salovey, P. (1997), 'What is emotional intelligence? In P. Salovey \& D. J. Sluyter (eds), Emotional development and emotional intelligence: Educational implications, pp. 3-34. New York: Harper Collins.

Maytum, J. C., Heiman, M. B., and Garwick, A. W. (2004), 'Compassion fatigue and burnout in nurses who work with children with chronic conditions and their families', Journal of Pediatric Health Care, 18:4, pp. 171-179.

Moss, H. and O'Neill, D. (2009), 'What training do artists need to work in healthcare settings?', Medical Humanities, 1, pp.1-5.

Mukherjee, S., Beresford, B., Glaser, A. and Sloper, P. (2009), 'Burnout, psychiatric morbidity, and work-related sources of stress in paediatric oncology staff: a review of the literature', Psycho-Oncology, 18:10, pp. 1019-1028.

Pantaleoni, J. L., Augustine, E. M., Sourkes, B. M., and Bachrach, L. K. (2014), 'Burnout in pediatric residents over a 2-year period: A longitudinal study', Academic Pediatrics, 14:2, pp. 167-172.

Parkinson, C. and White, M., (2013), 'Inequalities, the arts and public health: Towards an international conversation', Arts and Health, 5:3, pp.177-189.

Pelander, T., and Leino-Kilpi, H. (2010), 'Children's best and worst experiences during hospitalisation', Scandinavian Journal of Caring Sciences, 24:4, pp. 726-733.

Sextou, P. (2016), Theatre for Children in Hospital: The Gift of Compassion, Bristol: Intellect. 
Sextou, P. and Hall, S. (2015), 'Hospital theatre: Promoting child well-being in cardiac and cancer wards', Applied Theatre Research, 3:1, pp. 67-84.

Stratton, T.D., Sauders, J.A., and Elam, C.L. (2008), 'Changes in medical students' emotional intelligence: an exploratory study', Teaching and Learning in Medicine, 20:3, pp. 279-84.

Thomas, D. R. (2006), 'A General Inductive Approach for Analyzing Qualitative Evaluation Data', American Journal of Evaluation, 27:2, pp. 237-246.

The Guardian Education (2013), 'The gender gap at universities: where are all the men?', https://www.theguardian.com/education/datablog/2013/jan/29/how-many-menand-women-are-studying-at-my-university. Accessed 3 October 2017.

Thompson, J. (2015), 'Towards an Aesthetics of Care', Research in Drama Education: The Journal of Applied Theatre and Performance, 20:4, pp. 430-441.

Torrissen, W. and Stickley, T. (2018), 'Participatory theatre and mental health recovery: a narrative inquiry', Perspect Public Health. 138(1):47-54. doi: 10.1177/1757913917723944.

Wimpenny, K. and Savin-Baden, M. (2014), 'Using theatre and performance for promoting health and wellbeing amongst the $50+$ community: an arts-informed evaluation', The International Journal of Social, Political and Community Agendas in the Arts, volume 8 (1): 47-64.

Wisker, G. (2009), The Undergraduate Research Handbook. London: Palgrave. 